\title{
KOMODIFIKASI ANAK DALAM PROGRAM ACARA REALITY SHOW DI TRANS TV
}

\author{
Agustinus Kardiman dan Haryo Windratno
}

\author{
Sekolah Tinggi Ilmu Komunikasi (Stikom) Interstudi Jakarta \\ Email : kardimandr@gmail.com
}

\begin{abstract}
Abstrak
This research is attempted to uncover forms, processes and ideologies associated with the commodification of children at those impressions by takes perspective of a critical discourse analysis of the commodification of children in the program "Janji Suci Raffi and Gigi" produced by Trans TV. Analysis used is critical discourse analysis Norman Fairclough. Fairclough critical discourse analysis is done in three stages: (1) analysis of texts; (2) the practice of discourse and (3) the practice of social culture. Based on discoveries of the analysis of texts Program "Janji Suci Raffi and Gigi", interviews with several sources and combined with the relevant libraries show that: (1) occurs commodification of children in the show program "Janji Suci Raffi and Gigi" in Trans TV; (2) The commodification of children occurs through the formation process of setting and moments by the production crew and Raffi through Rafatar to show patterns and behaviors as a toddler; (3) The ideology behind the process of commodification of children is a capitalist ideology. The capitalist ideology in Trans TV due to Trans TV is a private broadcasting media who have the goal of business and profit.
\end{abstract}

Key words : realirty show, commodification, critical discourse, ideology

Riset ini berupaya mengungkap bentuk, proses dan ideologi yang berkaitan dengan komodifikasi anak pada tayangan "Reality Show." Perpestif penelitian.menggunakan analisis wacana kritis komodifikasi anak pada tayangan program "Janji Suci Raffi dan Gigi” yang diproduksi oleh Trans TV. Analsis wacana kritis Norman Fairclough untuk mengungkap praktek komodifikasi dalam content media dalam tayangan "Janji Suci Raffi dan Gigi” di Trans TV. Analisis ini dilakukan dalam tiga tahap yaitu (1) analisis teks; (2) praktik wacana dan (3) praktik sosialkultur. Hasil penelitian pada analisis teks Porgram "Janji Suci Raffi dan Gigi", wawancara dengan beberapa narasumber dan dipadukan dengan sumber referensi yang relevan menunjukkan bahwa : (1) terjadi komodifikasi anak dalam tayangan program "Janji Suci Raffi dan Gigi" di Trans TV; (2) Komodifikasi anak terjadi melalui proses pembentukkan setting dan momen yang dilakukan oleh crew produksi dan Raffi terhadap Rafatar untuk memperlihatkan pola dan tingkah laku anak balita; (3) Ideologi dibalik proses komodifikasi anak adalah ideologi kapitalis. Ideologi kapitalis tampak dalam praktek komodifikasi dan pertukaran nilai dan media Trans TV mendapatkan sponsor iklan. Masuknya iklan menjadi pendapatan industri media tersebut.

Kata kunci : reality show, komodifikasi, wacana kritis, ideology 


\section{Pendahuluan}

Persaingan antar televisi swasta di Indonesia semakin ketat. Sejak era reformasi, televisi swasta tumbuh dan berkembang pesat. Ada 15 stasiun televisi swasta mengudara di Indonesia, antara lain : RCTI, Indosiar, MNCTV, ANTV, SCTV, Global TV, Trans TV, Trans7, Metro TV, TV One, Jak-TV, Elsinta TV, Net TV, Kompas TV, CNN Indonesia dan R-TV. Persaingan antar TV swasta tersebut berdampak pada persaingan program acara televisi untuk mendapatkan sebanyak mungkin jumlah pemirsa. Semakin menarik suatu acara tv, maka akan semakin menaikkan rating suatu program acara. Suatu program acara yang rating - nya tinggi akan berimplikasi pada pendapatan iklan. .

Adanya persaingan ketat tersebut menuntut para pemilik modal di industri media harus kreatif dan inovatif dalam membuat content medianya, agar tidak ditinggalkan oleh pemirsanya. Pemilik media harus memiliki strategi bersaing untuk mempertahankan eksistensi dan pangsa pasarnya. Untuk memenangkan persaingan, stasiun
TV swasta terjebak dalam produksi penayangan content yang cenderung mengeksploitasi anak - anak, perempuan dan nilai kemanusiaan lainnya, untuk mengejar keuntungan komersial, bahkan mengabaikan etika dan moral dengan melakukan komodifikasi program acaranya.

Dalam mengkonsumsi program acara, penonton televisi sadar bahwa apa yang mereka tonton adalah suatu pesan (content) yang mereka butuhkan untuk memenuhi kebutuhan : informasi, hiburan, dan relaksasi. Teori Uses and Gratifications menyatakan bahwa orang secara aktif mencari media tertentu dan mengkonsumsi pesan (content) tertentu untuk mendapatkan manfaat dan kepuasan yang dibutuhkan (Turner, 2008:101). Jika khalayak media televisi menonton suatu program acara TV, yang merepresentasikan sosok artis dalam kehidupan nyata di masyarakat, maka akan tergambar realitas sosok artis dalam potret kehidupannya dalam tayangan TV. Realitas media yang tampil dalam penayangan TV adalah potongan dari sebagian besar kehidupan artis tersebut, dan tidak 
mencerminkan secara nyata dalam kehidupan sebenarnya.

Tayangan TV yang menampilkan kehidupan nyata sosok artis dalam sebuah program acara TV dikenal dengan acara, " Reality Show," Program acara ini banyak diminati oleh para pemirsa $\mathrm{TV}$, terutama penggemar sosok artis tertentu. Program ini mampu menarik banyak penonton, dan mampu menaikkan ratingnya. Reality Show merupakan salah satu program yang sering kita jumpai pada acara stasiun televisi swasta pada umumnya. Menjamurnya tayangan Reality Show tidak terlepas dari alasan ekonomis untuk mendapatkan keuntungan dengan mengeksploiatsi program tersebut dalam domain kapitalistik dengan melakukan komodifikasi content media.

Program acara Trans TV dengan judul, “ Janji Suci Raffi dan Gigi " merupakan salah satu tayangan televisi yang menampilkan kehidupan nyata sosok artis dalam acara reality show. Kehadiran tayangan ini tidak lepas dari suksesnya Trans TV yang secara langsung menyiarkan prosesi akad nikah hingga resepsi pernikahan artis tenar bernama Raffi Ahmad dan Nagita Slavina, dalam program acara, “ Menuju Janji Suci Raffi dan Gigi di Penghujung Tahun 2014." Ketenaran artis Raffi dan Gigi ternyata dieksploitasi lebih lanjut oleh stasiun Trans TV dalam tayangan lahirnya Rafatar, anak pertama dari pasangan artis Rafi dan Gigi. Tayangan ini menampilkan kehidupan keseharian Rafatar dalam masa pertumbuhan anak. Kelucuan dan cinta kasih kedua orangtuanya menjadi komoditas tontotan yang menarik bagi penggemar artis tersebut. Raffi dan Gigi merupakan artis papan atas yang memiliki tingkat popularitas tinggi. Program acara yang dibintanginya dalam setiap program TV mampu menarik pemirsa dan menarik sponsor iklan untuk menayangkan produknya di acara tersebut. Tingkat popularitas Raffi dan Gigi dapat kita ketahui melalui akun media sosial, seperti Instagram RAFFINAGITA1717 yang memiliki followers kurang lebih 10 juta followers per 10 Mei $2016^{1}$. Artinya, sebanyak kurang lebih 10 juta orang ingin mengetahui lebih

\footnotetext{
${ }^{1}$ Data diperoleh dari media sosial Instagram Raffi Ahmad dan Nagita Slavina
} 
jauh seperti apa sosok Raffi dan Gigi melalui akun instagram yang menampilkan foto - foto dan video. Gambar I.2 Instagram Raffi dan Gigi

Selain akun istagram, pasangan ini juga memiliki akun di situs youtube, dimana situs ini dapat menampilkan tayangan video dengan durasi yang lebih panjang. Kehidupan sehari - hari Raffi dan Gigi terekam dan dapat disaksikan oleh masyarakat dengan hanya membuka akun youtube mereka dengan nama Rans Entertainment. Pelanggan akun youtube Raffi dan Gigi juga tidak sedikit yaitu 53.893 pelanggan per 10 Mei $2016^{2}$, dan angka ini akan terus bertambah atau berkurang sesuai dengan tingkat popularitas yang menurun atau terus naik. Hal ini dapat membuktikan bahwa popularitas Raffi dan Gigi semakin eksis dan diminati oleh penggemarnya.

Tayangan Reality Show Rafatar dalam kehidupan keseharian ini merupakan kelanjutan kesuksesan Trans TV dalam menayangkan acara

${ }^{2}$ Data diperoleh dari situs youtube Channel Rans Entertainmet
"Reality Show" tentang prosesi akad pernikahan Raffi dan Gigi, kemudian dilanjutkan dengan tayangan acara yang memperlihatkan kehidupan keseharian keluarga Rafi Ahmad dan Gigi, yang penuh dinamika dalam kehidupan pasangan suami - isteri. Program ini memberikan informasi hiburan yang menarik tentang kehidupan Rafi dan Gigi dalam berkeluarga. Daya tarik kehidupan Rafi dan Gigi terus diikuti Trans TV dengan menampilkan kelahiran dan perkembangan anak pasangan Rafi Ahmad dan Gigi. Ternyata, program ini menarik dan mampu membuat penggemar artis Rafi dan Gigi itu ingin tahu bagaimana kehidupan anak seorang artis terkenal, Rafatar dalam masa pertumbuhannya.

Program acara Trans TV dalam "Reality Show," menampilkan Rafatar, mendapat penerimaan positif dari penggemar Trans TV, terutama penggemar Rafi dan Gigi. Rafatar sebenarnya adalah sosok bayi seperti pada umumnya. Namun, karena ketenaranan orang tuanya sebagai artis, maka Rafatar terimbas oleh ketenaran Rafi dan Gigi. Kehidupan Rafatar yang tumbuh, lucu dan menggemaskan itu membuat para 
penonton tv terhibur dan terkadang membuat tertawa dengan tingkah lakunya. Dalam konteks tayangan ini, Rafatar terlihat berbeda dengan anak - anak lainnya, kemana pun Rafatar pergi dan apa pun yang dilakukan olehnya terekam secara ekslusif oleh kamera crew Trans TV. Dengan adanya tayangan ekslusif ini, masyarakat bisa melihat secara langsung seperti apa polah dan tingkah laku anak ini.

Trans TV sebagai stasiun TV yang menyiarkan program reality show yang berjudul Janji Suci Raffi dan Gigi ditayangkan setiap hari mingu pukul 16:30 WIB dalam durasi 30 menit. Program tayangan “Janji Suci Raffi dan Gigi" yang menampilkan Rafatar dalam ratusan episode memiliki indikasi adanya ekpsloitasi anak dalam bentuk komodifikasi pada content media. Rafatar menjadi produk yang dijual kepada publik dan sponsor iklan. Proses komodifikasi dimulai ketika para crew produksi dengan kameranya mengemas dalam bentuk pesan yang menampilkan kehidupan Rafatar.

Menurut Dr. Philip Kitley (Subandy, 2011: 231) televisi merupakan media komunikasi massa untuk menyebarluaskan sajian gaya hidup, gaya perilaku, dan representasi diri yang berlebihan. Program Acara Trans TV dalam, "Janji Suci Raffi dan Gigi" cenderung menampilkan gaya hidup dan perilaku selebritis dalam kehidupan kelas atas, menjadi cermin budaya masa kini yang ingin ditampilkan produksi industri media untuk menjadi komoditas hiburan, yang memiliki nilai untuk dipertukarkan. Proses pertukaran ini menjadi bagian fungsi kapitalistik, dengan mengeksploitasi pekerja industri TV dan artis menjadi means of production dan menghasilkan keuntungan bagi produsennya.

Perolehan rating yang tinggi merupakan tujuan utama dari industri media untuk mendapatkan keuntungan komersial dari proses komodifikasi content media. Menurut Mazhab Frankfurt, industri budaya media mencerminkan konsolidasi fetisisme komoditas, dimana dominasi asas pertukaran dan meningkatnya proses produksi didominasi oleh kapitalis produsen. Pekerja industri hanyalah sebagai alat untuk menghasilkan produk 
untuk dipertukarkan nilainya. Dalam proses pertukaran tersebut, buruh atau pekerja dirugikan, karena keuntungan hasil pertukaran tersebut dinikmati kaum kapitalis. Komoditas Industri budaya membentuk selera dan kecenderungan masa, sehingga mencetak kesadaran mereka dengan cara menanamkan keinginan mereka atas Kebutuhan - Penelitian ini bertujuan untuk mengetahui proses komodifikasi tayangan " Reality Show" yang menampilkan Rafatar dalam acara Trans TV. Tayangan ini dikemas dalam bentuk penampilan kehidupan nyata keluarga Raffi Ahmad dan Nagita Slavina pada tayangan "Janji Suci Raffi dan Gigi”.

Menurut Mosco dalam Yorita (2005:28), ada 3 (tiga) konsep penerapan teori ekonomi politik dalam industri komunikasi, yaitu komodifikasi, spasialisasi dan strukturisasi. Komodifikasi mengacu pada pemanfaatan barang dan jasa dari sisi kegunaannya, yang kemudian ditransformasikan menjadi komoditas yang nilainya ditentukan oleh pasar. Spasialisasi merupakan proses mengatasi hambatan ruang dan dalam kehidupan sosial oleh perusahaan media dalam bentuk perluasan usaha. Sedangkan strukturisasi merupakan proses penggabungan human agency dengan proses perubahan sosial ke dalam analisis struktur.

Dalam konteks komodifikasi, Theodor Adorno dan Max Horkheimer (1979:123) mempunyai pandangan bahwa munculnya konsep komodifikasi karena perkembangan suatu industri budaya, dimana komodifikasi diartikan sebagai produksi benda budaya (musik, film, busana, seni dan tradisi), diproduksi secara massal oleh industri budaya, yang menghasilkan produk budaya yang tidak otentik / palsu, manipulatif, dan terstandarisasi. Dalam hal ini, masyarakat / khalayak baik secara sadar dan tidak, telah digerakan secara masif seolah sangat membutuhkan produk budaya tersebut. Masyarakat diposisikan seolah - olah sebagai subjek, padahal mereka adalah objek. Dalam perspektif ini, budaya tidak lagi lahir dari masyarakat sebagaimana yang dipahami dalam dengan benar, namun diproduksi dan direproduksi oleh kaum kapitalis atau penguasa dan pemilik modal untuk mendapat suatu keuntungan. Produk budaya 
yang dihasilkan oleh industri budaya memanipulasi masyarakat yang tak sekedar berbasis konsumsi, tapi juga menjadikan semua artefak budaya sebagai produk industri, dan komoditas.

Dalam teori kajian budaya, para peneliti memusatkan perhatiannya pada elite sosial dalam menjalankan media untuk mendapatkan keuntungan dan menyebarkan pengaruh pada masyarakat (J.Baran dan Dennis, 2010). Media digunakan untuk menciptakan dan memasarkan komoditas budaya sebagai upaya mempertahankan posisi media yang dominan dalam tatanan sosial serta menghasilkan keuntungan bagi para elite media

Dalam industri budaya, selain komodifikasi yang memperlakukan produk-produk sebagai komoditas untuk diperdagangkan, juga cenderung terjadi standarisasi dan masifikasi. Standarisasi berarti menetapkan kriteria tertentu yang memudahkan produk - produk industri budaya itu mudah dicerna oleh khalayaknya. Adapun masifikasi berarti memproduksi sebagai hasil budaya dalam jumlah massal agar dapat meraih pangsa pasar seluasluasnya. Dalam perkembangan industri ini akhirnya menghasilkan apa yang disebut dengan budaya populer (Lukmantoro, 2004).

Dengan demikian komodifikasi dapat diartikan sebagai sebuah proses menjadikan nilai guna menjadi nilai tukar melalui perubahan produk yang nilainya ditentukan oleh kemampuannya untuk memenuhi kebutuhan individu sosial ke dalam produk yang nilainya ditentukan oleh apa yang dapat dibawanya di pasar.

\section{Metodologi}

Dalam penelitian ini menggunakan perspektif ekonomi politik melihat dengan media tidak terlepas dari kepentingan pemilik modal, negara atau kelompok lainnya. Dengan kata lain, media menjadi alat dominasi dan hegemoni masyarakat. Proses dominasi ini menunjukkan adanya penyebaran dan aktivitas komunikasi masa yang sangat di pengaruhi oleh struktur ekonomi politik masyarakat yang bersangkutan. Implikasi logisnya adalah realitas yang dihasilkan oleh media besifat bias dan terdistorsi. 
Kajian ekonomi politik memiliki beberapa varian, yakni instrumentalisme, kulturalisme dan strukuralisme. Pada varian instrumentalisme memberikan penekanan pada determinisme ekonomi, dimana segala sesuatu pada akhirnya akan dikaitkan secara langsung dengan kekuatan - kekuatan ekonomi. Perspektif ini cenderung menempatkan agencies pada posisi lebih dominan dalam suatu struktur atau kultur. Kelas yang mendominasi adalah kapitalis dengan kekuatan ekonominya. Dalam hal ini, menempatkan media sebagai instrumen dominasi yang dapat digunakan oleh pemilik modal atau kelompok penguasa lainnya untuk memberikan arus informasi publik sesuai dengan kepentingannya dalam sistem pasar komersial (Sunarto, 2009:14).

Menurut Mosco dalam Yorita (2005:28), ada 3 konsep penerapan teori ekonomi politik dalam industri komunikasi, yaitu komodifikasi, spasialisasi dan strukturisasi. Komodifikasi mengacu pada pemanfaatan barang dan jasa dari sisi kegunaannya, yang kemudian ditransformasikan menjadi komoditas yang nilainya ditentukan oleh pasar. Spasialisasi merupakan proses mengatasi hambatan ruang dan dalam kehidupan sosial oleh perusahaan media dalam bentuk perluasan usaha. Sedangkan strukturisasi merupakan proses penggabungan human agency dengan proses perubahan sosial ke dalam analisis struktur.

Melihat fenomena popularitas Raffi Ahmad yang berujung pada tingginya nilai jual anaknya yang bernama Rafatar, kemudian mengindikasikan adanya transformasi nilai, dimana media dalam arti disini Trans TV dengan gamblangnya menampilkan keseharian Rafatar yang dikemas dalam bentuk tayangan reality show, dengan indikasi adanya komodifikasi anak yang dilakukan oleh pihak Trans TV untuk mendapatkan rating yang baik dengan berujung pada laba perusahaan.

Proses komodifikasi menjelaskan cara kapitalisme mencapi tujuan - tujuan mengakumulasikan kapital atau merealisasikan nilai melalui 
transformasi nilai guna menjadi nilai tukar. Melalui pengumpulan komoditas yang luar biasa, kapitalisme menghadirkan dirinya sendiri ke dalam bentuk perwujudan nyata.

Dalam pandangan Marxian, komoditas mengarah pada relasi sosial eksploitatif melalui naturalisasi kehadirannya. Sebuah barang hadir pada kita sebagai sebuah komoditas dengan seperangkat nilai guna dan nilai tukar yang ditandai dengan harga pembeliannya. Nilai guna dan nilai tukar barang tersebut cenderung mempesonakan karena kemampuan untuk menangani benda tersebut telah mengantarkan pada pembentukan pembagian tenaga kerja secara internasional yang menyetarakan relasi produksi sesuai dimensi kelas, gender, nasionalitas dan spasialitas. Pemesonaan (mistifikasi) komoditas semacam itu oleh Marx disebut sebagai pemujaan komoditas (commodity fetishism) di mana komoditas tidak hanya mengentalkan relasi sosial dan berisi perjuangan nilai, tetapi mengambil kehidupan dan kekuasaan atas pemiliknya (sebagai produser atau konsumen). Theodor Adorno dan

Max Horkheimer

(1979:123) mempunyai pandangan bahwa munculnya konsep komodifikasi karena perkembangan suatu industri budaya, dimana komodifikasi diartikan sebagai produksi benda budaya (musik, film, busana, seni dan tradisi), diproduksi secara massal oleh industri budaya, yang menghasilkan produk budaya yang tidak otentik/palsu, manipulatif, dan terstandarisasi.

Pada penelitian ini peneliti menggunakan analisis wacana Norman Fairclough seperti dikutip oleh Yoce Aliah Darma (2009:81) yang meliputi tiga dimensi yaitu analisis teks, analisis pemrosesan dan wacana praktis, dan analisis sosial (praksis sosiokultural, kontruksi masyarakat). Dalam model ini, selain teks utama juga ada teks - teks lain yang diteliti.

Teks dalam hal ini buka hanya tulisan tapi mengacu pada bahasa yang digunakan oleh media. Menurut Corner (2009: 294-295), teks mengacu pada serentang aktifitas dan bentuk dalam publikasi, televisi, film dan tampilan dan reproduksi visual yang menunjuk pada bagaimana 
suatu bahasa secara beragam digunakan di semua dimensinya melalui orang - orang yang berbeda dalam profesi media.

Bagi Fairclough, analisis teks sendiri tidak memadai bagi analisis wacana dan tidak menjelaskan hubungan antara struktur dan proses kultural dan kemasyarakatan. Untuk itu diperlukan perspektif interdisipliner yang menggabungkan analisis tekstual dan sosial. Keuntungan yang bisa diambil dengan pedoman pada tradisi makrososiologis adalah bahwa tradisi ini menganggap bahwa praktik sosial dibentuk oleh struktur sosial dan hubungan kekuasaan. Ironisnya masyarakat tidak sadar atas proses itu.

$$
\text { Kontribusi tradisi }
$$

interpretatif adalah memberikan pemahaman tentang bagaimana masyarakat secara aktif menciptakan dunia yang terkait pada kaidah dalam praktik sehari - hari. Selanjutnya, Fairclough dalam Udi Rusadi (2015: 119) membagi analisis wacana menjadi 3 (tiga) dimensi, yaitu: teks, discourses practice dan sosiocultural practice.

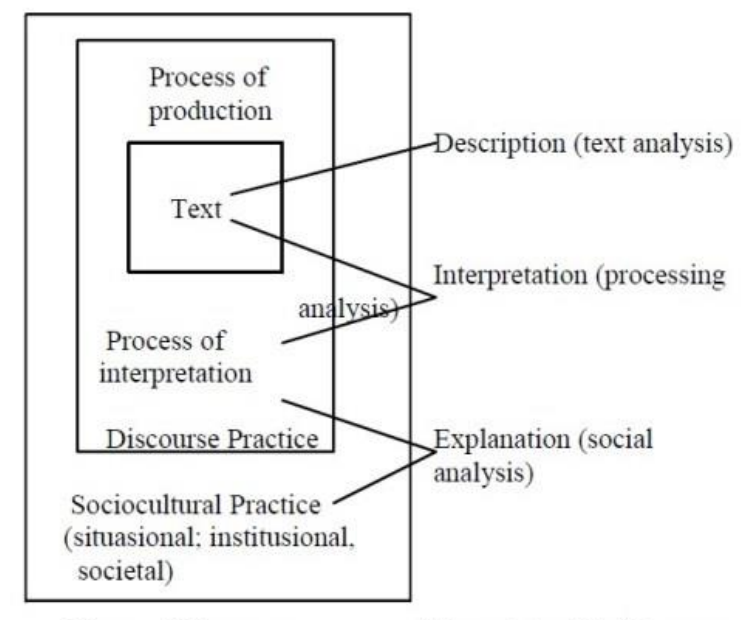

Dimensi Discourse Dimensi Analisis Discourse

Gambar III.1 Kerangka Analisis Intertekstual Fairclough 
Konsep yang dibentuk Norman Fairclough menitikberatkan pada 3 (tiga) level. Pertama, analisis mikrostruktur (ada pada level teks), yakni menganalisis teks dengan cermat dan fokus supaya dapat memperoleh data yang dapat menggambarkan representasi teks. Secara detil aspek yang dikejar dalam tingkat analisis ini adalah garis besar atau isi teks, lokasi, sikap dan tindakan tokoh tersebut dan seterusnya. Setiap teks secara bersamaan memiliki 3 (tiga) fungsi, yaitu representasi, relasi, dan identitas. Fungsi representasi berkaitan dengan cara - cara yang dilakukan untuk menampilkan realitas sosial ke dalam bentuk teks. Dengan demikian representasi pada dasarnya ingin melihat bagaimana seseorang, kelompok, tindakan, kegiatan ditampilkan dalam teks. Relasi berhubungan dengan bagaimana partisipan dalam media berhubungan dan ditampilkan dalam teks. Identitas berkaitan dengan bagaimana identitas media ditampilkan dan dikontruksi dalam teks pemberitaan.

Kedua, analisis mesostruktur (level praktek wacana) yang terfokus pada dua aspek yaitu produksi dan konsumsi teks. Praktik wacana meliputi cara-cara para pekerja media memproduksi teks. Hal ini berkaitan dengan pekerja media itu sendiri selaku pribadi, sifat jaringan kerja wartawan dengan sesama pekerja media lainnya, pola kerja media sebagai instiusi, seperti cara meliput acara, menulis acara, sampai menjadi tontonan di dalam media. Pada praktek konsumsi dianalisis bagaimana khalayak memberikan tanggapan terhadap teks.

Ketiga, analisis makrostruktur (proses wacana) terfokus pada fenomena di mana teks dibuat. Praktik social - budaya ini menganalisis tiga hal yaitu ekonomi, politik (khususnya berkaitan dengan isu-isu kekuasaan dan ideologi), dan budaya (khususnya berkaitan dengan nilai dan identitas) yang juga mempengaruhi institusi media dan wacananya. Pembahasan praktik sosial budaya meliputi 3 (tiga) tingkatan, yakni (1) tingkat situasional, berkaitan dengan produksi dan konteks situasinya, (2) tingkat institsional, berkaitan dengan pengaruh institusi secara internal maupun eksternal, dan (3) tingkat 
sosial, berkaitan dengan situasi yang lebih makro, seperti sistem politik, sistem ekonomi dan sistem budaya masyarakat secara keseluruhan.

Hasil Penelitian dan Pembahasan
Dari beberapa cuplikan yang dianalisis dalam teks, praktek wacana (discourse practice) dan wacana budaya (social discourse) dapat diuraikan dalam table uraian tersebut di bawah ini:

\section{a. Hasil penelitian}

Tabel 1 Hasil Temuan Analisis Teks

\begin{tabular}{|c|c|}
\hline Level Analisis & Temuan \\
\hline Representasi & $\begin{array}{l}\text { Rafatar seorang balita yang dieksploitasi dan ditampilkan } \\
\text { serta menjadi objek utama dalam program JSR\&G }\end{array}$ \\
\hline Relasi & $\begin{array}{l}\text { Ditemukan } 4 \text { (empat) partisipan yaitu Raffi, Tim Produksi } \\
\text { (Trans TV), Rafatar dan pemasang iklan Incharge. } \\
\text { Pemasang iklan incharge masuk dalam relasi ini karena } \\
\text { secara langsung produk mereka terlihat nyata dalam } \\
\text { tayangan. Terkait masalah relasi ini, maka posisi } \\
\text { kedudukan Raffi dan Tim Produksi sama. Posisi Rafatar } \\
\text { ada dibawah Raffi dan Tim. Sebab Rafatar masih balita } \\
\text { dan tidak dapat menolak keinginan mereka (Raffi dan Tim } \\
\text { Produksi). Lalu pemasang iklan incharge disini relatif } \\
\text { lebih rendah dibanding tim produksi sebab untuk } \\
\text { memasangkan produknya, pemasang iklan wajib } \\
\text { mengikuti aturan pemasangan iklan yang ada dalam } \\
\text { kebijakan pihak Trans TV }\end{array}$ \\
\hline Identitas & $\begin{array}{l}\text { - Tim Trans TV menempatkan dirinya secara terang- } \\
\text { terangan untuk mengeksploitasi Rafatar karena salah } \\
\text { satu crew ada yang in frame untuk memberikan } \\
\text { arahan pada konten tayanggan. } \\
\text { - Raffi serta Gigi sebagai orang tua Rafatar secara } \\
\text { biologis juga 'memperkerjakan' Rafatar. Terlihat jelas } \\
\text { dalam tayangan mereka bahwa berdualah sebagai } \\
\text { partisipan yang juga aktif mengeksploitasi anaknya. } \\
\text { - Rafatar sebagai balita dipekerjakan dengan setting } \\
\text { yang nyaris tidak terdeteksi oleh awam, karena } \\
\text { ditampilkan dengan segala kemewahan dan sistem } \\
\text { kerja yang fleksibel. }\end{array}$ \\
\hline
\end{tabular}

Sumber : hasil analis peneliti 
Data temuan dari level Discourse Practice berdasrakan wawancara dengan Aris Ananda selaku Development Program Trans TV dan Bisma Ali Satari selaku Executive Producer program JSR\&G, dapat dijelaskan proses terjadinya teks dalam hal ini program acara reality show JSR\&G di sub bab ini.

Program JSR \& G sebelum berubah format menjadi reality show, sebelumnya adalah program acara live report acara prosesi pernikahan Raffi dan Gigi pada akhir tahun 2014 lalu dengan judul acara yang sama yaitu “Janji Suci Raffi \& Gigi”, setelah pihak Trans TV melihat adanya peluang, kemudian kerjasama antara Trans TV dan Raffi dilanjutkan untuk membuat sebuah program reality show mengenai keseharian keluarga Raffi, ide ini berasal dari program reality show artis internasional Kim Khadarsian yang menayangkan kesehariannya, hal ini seperti yang diungkapkan Bisma selaku Executive Producer program JSR \& G.

Ide awal hingga eksekusi produksi program JSR \& G sangat singkat, Trans TV meyakini artis Raffi Ahmad memiliki tingkat popularitas tinggi pada saat ini, sehingga program ini diproyeksikan akan memberikan keuntungan bagi Trans TV. Seperti yang dikatakan oleh Aris Ananda selaku Development Program Trans TV.

“...untuk program yang sifatnya Star Driven itu relative lebih cepat dalam proses eksekusinya, dalam arti dari proses perencanaan hingga produksi tidak membutuhkan waktu tidak terlalu lama. Ini dikarenakan Star Driven itu biasanya Tim melihat sebuah momen, dalam konteks ini pernikahan Raffi dan Gigi cukup menyita perhatian masyarakat, nah momen inilah yang diambil oleh Tim produksi untuk mencoba menghasilkan sebuah program ekslusif dengan jenis reality show..."

Kerjasama kesepakatan antara Trans TV dan Raffi kemudian direalisasikan dalam bentuk tayangan perdana program Reality Show JSR \& G, proses pembuatan episode perdana relative cepat, setelah peneliti konfirmasi kepada Bisma selaku Executive Producer, Bisma mengungkapkan bahwa program ini dibuat tanpa adanya dami terlebih dahulu, episode perdana adalah dami sekaligus tayangan perdana, berikut penjelasan Bisma terkait hal ini.

"Raffi orang entertain di depan layar, dan saya orang di belakang layar, nah ketemu ne, klop. Waktu itu kita bikin episode pertama itu 
bisa dibilang sangat mendadak banget, karena waktu itu Raffi ngajak saya untuk ikut sama dia menghadiri pernikahan temennya di Medan, pergilah saya kesana, nah jadilah itu episode pertamanya..."

Data Temuan Sociocultural Practice berdasarkan asumsi bahwa konteks sosial yang ada di luar media berpengaruh pada wacana yang muncul di media (Eriyanto, 2011:320). Dengan menggunakan analisa wacana Norman Fairclough maka temuan penelitian dibedakan menjadi dua yakni aspek Sosiocultural practice yang diperoleh melalui hasil wawancara dengan Aris Ananda selaku Program Development Trans TV dan Bisma Ali Satari sebagai Executive Producer Trans TV Program Janji Suci Raffi dan Gigi (JSR \& G). Wawancara juga dilakukan dengan pemirsa sesuai dengan target audiens. Dari analisis Sosiocultural practice yang diperoleh temuan sebagai berikut.

Temuan aspek Sociocultural Practice dari wawancara:

1. Pada level institusi internal Trans $\mathrm{TV}$, tepatnya lebih pada organisatoris hierarkis yakni keputusan committee (Direksi, Kepala Divisi Produksi, Kepala Departemen Produksi,
Development Program, Marketing) atau keputusan bersama pada saat meeting.

2. Pada level institusi internal Trans TV maupun keluarga Rafatar sendiri. Ini terjadi pada seluruh episode yang dijadikan sampel, yakni episode 13 Desember 2015, epidose 17 April 2016, episode 24 April 2014, dan eposide 1 Mei 2016. Pada episode episode tersebut terdapat orientasi konten siar terhadap Rafatar

3. Faktor Sociocultural Practice pada level situasional, yakni ketika tim produksi berupaya mencari momen yang tepat untuk dijadikan tema pada episode yang akan digarap. Sebenarnya momen juga digunakan tim produksi Trans TV diawal sekali ketika memproduksi program Janji Suci Raffi dan Gigi. Pada setiap episode proses produksi komodifikasi mempertotonkan kehidupan pribadi Rafi Ahmad, Gigi dan anaknya Rafatar. Program JSR \& G, mengeksploitasi kehidupan pribadi artis menjadi fetisisme komoditas gaya baru. Produk seni budaya diubah menjadi budaya media popular dan ditayangkan secara massif untuk mendapatkan 
rating tinggi, menurut Adorno praktek tersebut disebut sadomasokistik dalam industri budaya massa dimana orang-orang membiarkan dirinya dimobilisasi oleh kepentingan industri media.

\section{b. Pembahasan}

Dari data temuan penelitian, Trans TV memanfaatkan momen ketenaran Raffi dan Gigi sebagai bintang yang selalu tampil setiap hari pada hampir semua stasiun televisi swasta. Ketenaran mereka dijadikan momentum untuk dibuatkan program Reality Show. Program Janji Suci Raffi dan Gigi (JSR\&G) diawali dengan berkonsep star driven ${ }^{3}$. Ini artinya Raffi dan Gigi sudah terlebih dahulu terkenal dan menjadi bintang, setelah itu barulah tim produksi merancangkan sebuah program. Rafatar yang merupakan anak balita dari pasangan Raffi serta Gigi tidak pernah secara sukarela menginginkan dirinya tampil di Trans TV atau memutuskan dirinya menjadi artis mengikuti kedua orang tuanya. Dalam kajian ekonomi politik media terdapat hubungan yang saling

\footnotetext{
${ }^{3}$ Hasil wawancara dengan Aris Ananda Development Program Trans TV
}

menguntungkan antara sumber produksi yakni Trans TV dan Raffi sebagai artis (Barret, 1996:186). Pada kasus Rafatar dari tayangan program acara tersebut, secara individu tidak memperoleh keuntungan apa - apa, karena posisinya masih balita. Namun ada sebagian hasil keuntunga yang diberikan dalam bentuk kebutuhan anak.

Pada semua sampel program JSR \& $G$ yang ditelaah selalu terdapat adegan dan ungkapan yang menggambarkan kasih sayang Raffi maupun Gigi kepada putranya Rafatar. Kejadian ini menurut Ibrahim dan Akhmad (2014:21-22) termasuk dalam kategori komodifikasi nilai - nilai. Adalah fitrah alami dan hal yang wajar jika orang tua menyayangi anaknya, entah itu diungkapkan dengan katakata ataupun dengan tingkah laku. Begitu juga yang terjadi dengan Raffi - Gigi ketika menyayangi Raffatar sebagai putranya. Akan tetapi pada pandangan Marx (dalam Ibrahim dan Akhmad, 2014:22) apapun yang ada dalam lingkaran kapitalisme merupakan komodifikasi. Kita pahami stasiun 
Trans TV bagian dari Trans Corp yang memiliki bisnis beragam mulai dari media, hotel dan properti, wahana hiburan dan finansial, retail, food and beverages dan maskapai penerbangan yang kesemuanya mengejar profit sudah jelas masuk kategori kapitalis. Bila merujuk pada pemikiran Croteau dan Hoynes ( 2006:17) CT Corp yang menjadi induk dari Trans TV masuk ke dalam kategori bisnis model pasar, dengan demikian berlaku hukum permintaan dan penawaran, dan ini jelas berdasar kapital. Kembali pada nilai kasih sayang yang terdapat pada tayangan JSR \& G maka dapat dipahami mengenai pemikiran Marx. Bila ungkapan kasih sayang yang bisa berupa verbal maupun non verbal oleh Raffi dan Gigi kepada anaknya dalam program JSR \& G yang seharusnya hal wajar sebenarnya adalah wujud dari komodifikasi.

\footnotetext{
Program JSR \& G yang dipertontonkan kepada khalayak sudah tidak lagi memiliki nilai estetis dan kualitas. Sebab hasrat berkarya baik dari si pembuat dalam konteks ini Trans TV serta Raffi maupun si penikmat karya tersebut dalam hal
}

ini penonton akan melebur dalam sebuah wadah yang berwujud program acara JSR \& G. Sehingga program acara yang ditayangkan di televisi ini bukan lagi sebuah karya yang berkualitas. Karena terdapat luruhnya budaya auratik berupa teks - teks, praktek - praktek budaya tinggi yang tereduksi oleh teknik reproduksi mekanis (Benjamin, 2006: 9) bisa berupa standar prosedur operasional pra produksi, produksi dan pasca produksi dan pemasang iklan. Konsep Benjamin tentang aura yang dikaitkan dengan reproduksi mekanistik karya seni. Lenyapnya aura melahirkan beragam interpretasi ulang. Di antaranya adalah terjadinya pergeseran budaya yang kemudian menjelma menjadi budaya populer atau budaya masa (mass culture). Budaya populer seringkali diandaikan sebagai sebuah kategori residual dalam perbandingannya terhadap budaya tinggi. Budaya populer sering dipahami sebagai sejenis budaya yang gagal memenuhi standar menjadi budaya tinggi. Ada distingsi yang cukup ekstrem di antara kedua jenis budaya ini saat budaya populer dimaknai sebagai kreasi yang 
diproduksi melalui produksi massal, sementara budaya tinggi adalah kreasi individual yang berhak mendapat apresiasi estetik. Proses masifikasi produksi budaya masal juga kerap dianggap sebagai praktek simbolik manipulatif, fantasi publik dan mimpi kolektif, yang secara pasif dan otomatis akan timpas dikonsumsi. (Walter, 2006: 19).

\section{Kesimpulan}

Hasil penelitian ini mempunyai implikasi teoretis pada level aplikatif terhadap kajian kritis dalam teori komodifikasi dan ekonomi politik media secara umum. Konsep komodifikasi yang merupakan pengembangan dari paradigma kritis memberikan deskripsi jelas bahwa praktek komodifikasi mengarah pada praktek eksploitasi anak sebagai sebuah

\section{DAFTAR PUSTAKA}

Buku:

Adorno, Theodor and Max Horkheimer.1972. Dialectic of Enlightment. Herder \& Herder Inc. New York. produk komoditas hiburan yang mampu dipertukarkan menjadi nilai komersial yang mendatangkan keuntungan bagi perusahaan media. Setiap tayangan programnya ada sponsor iklan yang membeli waktu dan ruang dengan memberikan imbalan uang sesuai dengan tarif iklannya. Perusahaan media mendapatkan keuntungan dari program acara hiburan tersebut. Semakin tinggi rating tayangan tersebut semakin banyak keuntungan atau pendapatan yang diperoleh perusahaan media. Di sini terjadi proses komodifikasi dalam industri media yang mendatangkan keuntungan bagi pemilik modal. Praktek ini merefleksikan prktek ideologi kapitalis.

Atmowiloto, Arswendo. 1986. Telaah Tentang Televisi. PT. Gramedia. Jakarta

Badara, Aris. 2012. Analisis Wacana: Teori, Metode, dan Penerapan Pada Wacana Media. Kencana Prenada Media Group. Jakarta. 
Baran, Stanley J dan Dennis K. Davis. 2010. Teori Komunikasi Massa Dasar, Pergolakan, dan Masa Depan. Salemba Humanika. Jakarta.

Barret, Boyd. 1995. The Analysis of Media Occupations and Profesionals in Boyd Barret, Oliver, and Chris Newbold, Eds. Approaches to Media: A reader. New York.

Benjamin, Walter. 2006. The Work of Art in the Age of Mechanical Reproduction in Meenakshi Gigi Durham (eds). Media and Culture Studies. Blackwall Publishing.

Darma, Yoce Aliah, 2009. Analisis Wacana Kritis. Yrama Media. Bandung.

Dosi, Eduardus. 2012. Media Massa dalam Jejaring Kekuasaan. PT. LKIS. Yogyakarta.

Effendy, Onong Uchjana. 2000. Ilmu Komunikasi: Televisi Siaran Teori dan Praktek. Remaja Rosdakarya. Bandung.

Eriyanto. 2011. Analisis Wacana: Pengantar Analisis Teks Media. LKiS. Yogyakarta.

Fiske, John. 1989. Understanding Popular Culture. London: Routledge.

Hall, Stuart. 1997. Mass Communication and Society. Tp. London.

Ibrahim, Idi Subandy dan Akhmad, Ali Bahcrudin. 2014.
Komunikasi dan Komodifikasi: $\quad$ Mengkaji Media dan Budaya dalam Dinamika Globalisasi. Yayasan Pustaka Obor Indonesia. Jakarta.

Jalaluddin, Rakhmat, 2002. Metode Penelitian Komunikasi. Bandung : PT. Remaja Rosdakarya.

Jorgensen, Marianne W dan Philips, Louis J. 2007. Analisis Wacana: Teori dan Meotode. Pustaka Pelajar. Yogyakarta.

Kriyantono, Rahmat 2006, Teknik Praktis Riset Komunikasi, Jakarta, PT Kencana Prenada Media Group.

Littlejohn, Stephen W dan Karen A Foss. 2009. Teori Komunikasi. Salemba Humanika, Jakarta.

McQuaill, Dennis. 2010. Mcquaill Mass Communication Theory. Sage Publication. London.

McQuail, Dennis. 2011. Teori Komunikasi Massa McQUAIL. Salemba Humanika. Jakarta.

Morrisan. 2005. Media Penyiaran: Strategi Mengelola Radio dan Televisi. Ramdina Prakarsa. Jakarta.

Morrisan. 2008. Manajemen Media Penyiaran: Strategi Mengelola Radio dan Televisi. Kencana Prenada Media Group. Jakarta. 
Mosco, Vincent. 1996. The Political Economy of Communication: Rethinking and Renewal. Sage Publication. London.

Narwaya, Tri Guntur. 2006. Matinya Ilmu Komunikasi. Resist Book. Yogyakarta.

Noor, Faizal Henry. 2010. Ekonomi Media. Rajawali Pers. Jakarta.

Pringle K. Peter, Starr F Michael, dkk. 1991. Electronic Media Management. Focal Press. London.

Richard West, Lynn H.Turner. 2008. Pengantar Teori Komunikasi: Analisis dan Aplikasi (Buku 2) (Edisi 3). Salemba Humanika. Jakarta.

Rusadi, Udi. 2015. Kajian Media Isu Ideologis dalam Perspektif: Teori dan Metode. PT. Raja Grafindo Persada. Jakarta.

Selby, Keith dan Ron Coedery. 1995. Hot to Study Television. Mc Millisan. London.

Set, Sony. 2008. Menjadi Perancang $\begin{array}{lr}\text { Program } & \text { Televisi } \\ \text { Profesional. } & \text { Andi. } \\ \text { Yogyakarta. } & \end{array}$

Sobur, Alex. 2009. Analisis Teks, Suatu Pengantar untuk Analisis. Wacana Analisis Semiotik dan Analisis Framming. PT. Remaja Rosdakarya. Bandung.

Strinati, Dominic. 2007. Popular Culture: Pengantar Menuju
Teori Budaya Populer. Jejak. Yogyakarta.

Sugiono. 2012. Metodologi Penelitian KuantitatifKualitatif dan $R \& D$. Alfabeta .Bandung

Sutrismo, Mudji dan Putranto, Hendar (ed). 2005, Teoriteori Kebudayaan. Kanisius. Yogyakarta.

Williams, Raymond. 1983. Keyword: A Vocabulary of Culture and Society. Fontana. London.

\section{Tesis:}

Basri, Irsyan. 2014. Komodifikasi Ritual Duata Pada Etnik Bajo di Kabupaten Wakatobi Provinsi Sulawesi Tenggara. Universitas Udayana. Denpasar, Bali.

Raharjo, Sumantri. 2011. Komodifikasi Budaya Lokal dalam Televisi (Studi Wacana Kritis Komodifikasi Pangkur Jenggleng TVRI Yogyakarta). Universitas Sebelas Maret. Surakarta.

Widyastuti, Dyah Ayu R. 2008. Studi Kasus mengenai Komodifikasi Upacara Religi Saraswati dalam Komunikasi Pemasaran Pariwisata Candi Ceto Kabupaten Karanganyar. Universitas Sebelas Maret. Surakarta.

\section{Jurnal :}

Musthofa, As'ad. 2012. Komodifikasi Kemiskinan Oleh Media 
Televisi. Magister Ilmu Komunikai Universitas Diponegoro. Semarang.

Sukmono, Banin Diar. 2012. Eksploitasi Tubuh Perempuan di Televisi Sebagai Ironi Kepribadian Indonesia. Program Studi Filsafat Univ. Gajah Mada. Yogyakarta.

\section{Youtube :}

https://www.youtube.com/watch?v=DxpHD3L7GA (13 desember 2015 "Lagu Untuk Rafatar").

https://www.youtube.com/watch?v= 99sMIG-VSDc (17 april 2016 "Rafatar Naik Motor").

https://www.youtube.com/watch?v= PsFdPW8NU8s (24 april 2016 "Masa Depan Rafatar").

https://www.youtube.com/watch?v= 8RuTSm0cbIM (1 mei 2016 "Warisan Untuk Rafatar").

https://www.youtube.com/watch?v= _sddSIiXmjw (22 Mei 2016 "Pantai Pertama Rafatar).

https://www.youtube.com/watch?v= Ee6Oj5aJNc0 (5 Juni 2016 "Rafatar Beli Sepeda Baru"). www.kpai.go.id

www.transtv.co.id

www.otomaniac.com

www.youtube.com

http://www.kompasiana.com/amirsya hoke/eksploitasianak_5520ece481331111771 9f89d 